\title{
Growth and Characterization of a New Semi-Organic Nonlinear Optical Crystal: Thiosemicarbazide Cadmium Acetate
}

\author{
K. Selvaraju ${ }^{\mathrm{a}, *}$, K.Kirubavathi ${ }^{\mathrm{b}}$, S. Kumararaman ${ }^{\mathrm{c}}$ \\ ${ }^{a}$ Department of Physics, Govt. Arts College, Ariyalur-621 713, India \\ ${ }^{\mathrm{b}}$ Department of Physics, Thiru Kolanjiapper Govt. Arts College, Virdudhachalam-606 001, India \\ c Department of Physics, Nehru Memorial College, Puthanampatti-621 007, India
}

*Corresponding author: selva_thrc@yahoo.com

\begin{abstract}
A new semi-organic nonlinear optical thiosemicarbazide cadmium acetate (TSCA) material has been synthesized. TSCA single crystals were grown from aqueous solution by slow evaporation method. The solubility of TSCA has been determined for various temperatures. The grown crystals were characterized by single crystal X-ray diffraction (XRD), FTIR, UV-Vis., thermal and second harmonic generation (SHG) analysis. Single crystal XRD study has been carried out to identify the lattice parameters. FTIR studies confirm the functional groups present in the grown crystal. Optical transmission studies have confirmed that the grown crystal is highly transparent. Thermogravimetric and differential thermal analyses reveal the good thermal stability of the material. The SHG conversion efficiency of TSCA was determined using Kurtz powder technique and found two times that of potassium dihydrogen orthophosphate (KDP).
\end{abstract}

Keywords: Growth from solution; Semiorganic; Nonlinear optical crystal

\section{INTRODUCTION}

Second order nonlinear optics is widely used to convert the frequency of coherent laser source. Applications such as laser based imaging, communication, remote switching and countermeasure systems require improved nonlinear optical materials to accomplish such conversions. A strong need continues to exist for lower cost, more efficient, higher average power materials for optical parametric amplifier operation and second harmonic generation throughout the blue-near-uv spectral region [1,2]. Much attention has been paid to organic nonlinear optical (NLO) materials 
due to their promising applications in optoelectronics technology [3] and the much larger nonlinear response, extremely fast switching time and convenient optimization routs through molecular engineering compared to the currently studied inorganic materials [4]. However, organic materials may suffer from problems, such as volatility, low thermal stability, mechanical weakness, etc. The need for materials which combine large nonlinear optical characteristics with resistance to physical and chemical attack has led to the investigation of semi-organics $[5,6]$.

Semi-organic materials have the potential for combining high optical nonlinearity and chemical flexibility of organics with the physical ruggedness of inorganic. Ligands like thiourea, allylthiourea, thiocyanate and thiosemicarbazide with $\mathrm{S}$ and $\mathrm{N}$ donors are capable to combine with metal to form stable complexes through coordinated bonds. These complexes show ligand to metal charge transfer by an electron movement form ligand to metal and metal to ligand in addition to $\pi-\pi^{*}$ conjugation. Metals with $\mathrm{d}^{10}$ configuration like zinc, cadmium, mercury readily combine with thiourea and thiosemicarbazide resulting in stable compounds with high optical nonlineatiry and good physiochemical behavior. Thiourea and thiosemicarbazide based organ metallic optical crystals like bis thiourea cadmium chloride, bis thiourea zinc acetate, bis thiourea bismuth chloride, thiosemicarbazide cadmium bromide hydrate, thiosemicarbazide cadmium chloride [7-11].

In the present investigation, attempts have been made to grow single crystal of TSCA for the first time and characterize them by single crystal X-ray diffraction (XRD), Fourier transform infrared (FTIR) analysis, optical transmission, thermal and SHG efficiency studies.

\section{EXPERIMENTAL PROCEDURE}

\subsection{Material Synthesis}

TSCA salt was synthesized using cadmium acetate (AR grade) and thiosemicarbazide (AR grade) in the stoichmetric ratio 1:1. The required quantity of cadmium acetate and thiosemicarbazide was estimated according to the following reaction:

$\mathrm{Cd}\left(\mathrm{CH}_{3} \mathrm{COO}\right)_{2}+\mathrm{NH}_{2}-\mathrm{NH}-\mathrm{CS}-\mathrm{NH}_{2} \longrightarrow \mathrm{Cd}\left(\mathrm{NH}_{2}-\mathrm{NH}-\mathrm{CS}-\mathrm{NH}_{2}\right)\left(\mathrm{CH}_{3} \mathrm{COO}\right)_{2}$

The calculated amount of cadmium acetate was first dissolved in the deionized water. Then thiosemicarbazide was added to the solution slowly with stirring. The prepared solution was led to dryness at room temperature. The purity of the synthesized salt was improved by successive recrystallization. The careful observation was taken for drying the prepared solution and the temperature was never allowed to exceed $50{ }^{\circ} \mathrm{C}$ so as to avoid decomposition of the solute molecules. 


\subsection{Solubility}

The solubility of TSCA was determined in the range of $30-45{ }^{\circ} \mathrm{C}$. The solubility was determined by dissolving the solute by stirring in water in an airtight container maintained at the relevant temperature. After attaining saturation, the equilibrium concentration of the solute was estimated gravimetrically. The same process was repeated to estimate the equilibrium concentration of the solute at various temperatures. Fig. 1 shows the solubility curve for TSCA at different temperatures.

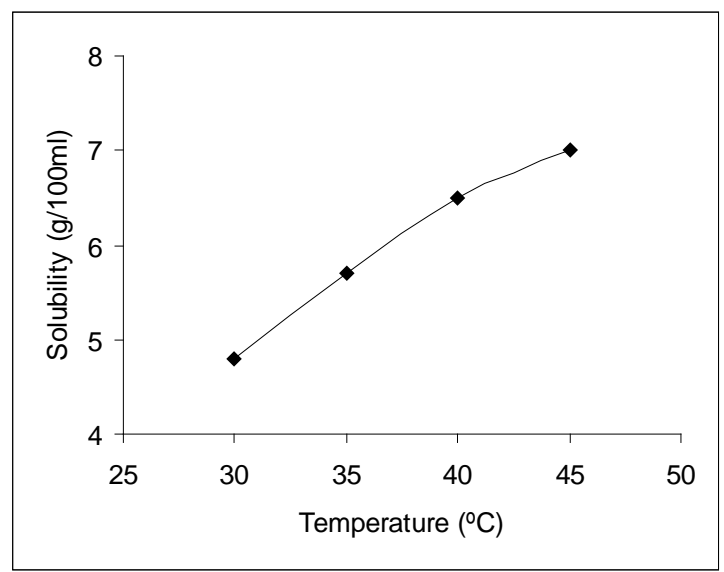

Fig. 1. Solubility curve of TSCA

\subsection{Growth of TSCA}

In the present study, TSCA crystals were grown by using slow evaporation technique. Recrystallized salt of TSCA was taken as a raw material. Saturated TSCA solution was prepared at room temperature with deionized water as solvent. The prepared solution was filtered with a microfilter. The solution was taken in vessels and closed with covers and kept in a dust-free atmosphere. The crystals were harvested when they attained an optimal size and shape. The grown crystals are shown in Fig.2.

\section{CHARACTERIZATION}

The single crystal x-ray diffraction analysis was carried out using ENRAF NONIUS CAD4 Xray diffractometer to identify the structure and to estimate the lattice parameter values. Fourier transform infrared spectrum of TSCA crystal was recorded by the $\mathrm{KBr}$ pellet technique using a BRUKER 66V FTIR spectrometer to confirm the vibrational structure of the crystalline compound with the range of wavenumber $400-4000 \mathrm{~cm}^{-1}$. UV-Visible spectrum was recorded in the range of 200-1400nm using VARIAN CARY 5E spectrometer. Thermal behavior of the 
grown sample was studied by using STA 1500 thermal analyzer. The NLO property of TSCA was tested by Kurtz powder SHG test using an Nd:YAG laser.

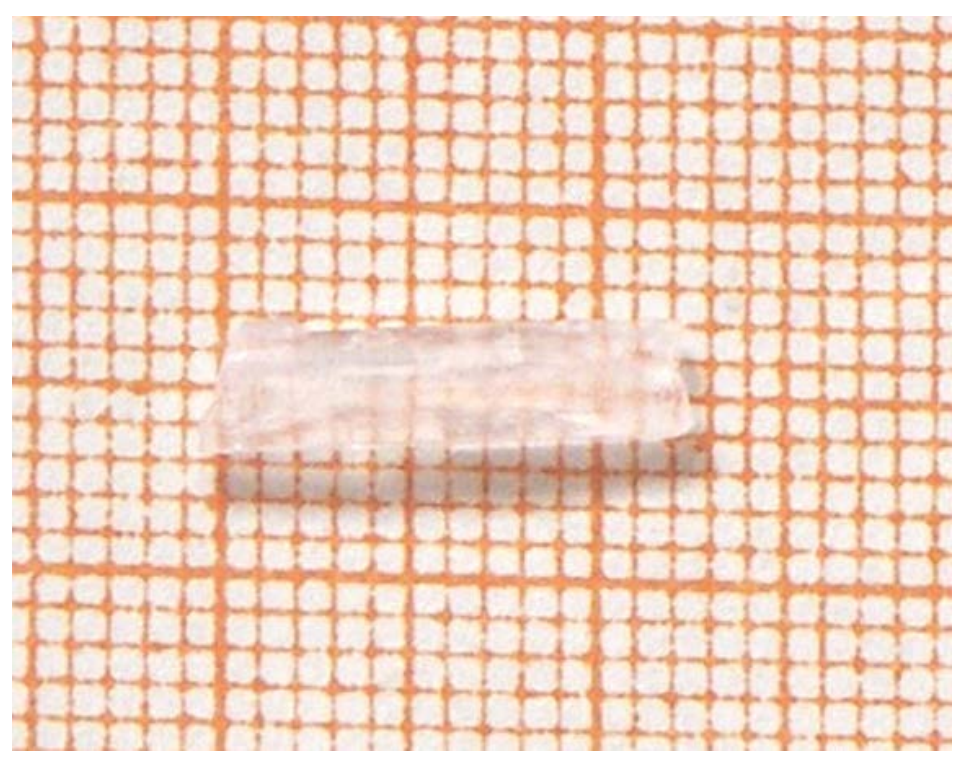

Fig. 2. As-grown TSCA crystal

\section{RESULTS AND DISCUSSION}

\subsection{Single Crystal XRD Analysis}

In order to estimate the crystal data, single crystal X-ray diffraction studies were carried out using Enraf Nonius CAD4 single crystal diffractometer. The structure was solved by direct method and refined by the full matrix least squares technique using SHELX program. It is observed that the grown TSCA crystal belongs to monoclinic system and the lattice parameter values are $\mathrm{a}=6.675 \mathrm{~A}^{\circ}, \mathrm{b}=10.569 \mathrm{~A}^{\circ}, \mathrm{c}=23.689 \mathrm{~A}^{\circ}$ and $\beta=109.20^{\circ}$.

\subsection{FTIR Analysis}

The FTIR spectral analysis of TSCA was carried out between 4000 and $400 \mathrm{~cm}^{-1}$. The observed spectrum is shown in Fig. 3. In the high energy region, there is a broad band between 2100 and $3500 \mathrm{~cm}^{-1}$. Intense sharp peak was observed at $3180 \mathrm{~cm}^{-1}$ due to $\mathrm{O}-\mathrm{H}$ vibration. The involvement of $\mathrm{NH}_{3}{ }^{+}$in hydrogen bonding is the evident by the fine structure of the band in the lower energy region. In the high energy region, the band observed at $2929 \mathrm{~cm}^{-1}$ is due to the $\mathrm{NH}_{2}$ bending vibration. The peak at $1418 \mathrm{~cm}^{-1}$ is due to symmetric $\mathrm{NH}_{3}{ }^{+}$bending. The bands appear in the region $1534 \mathrm{~cm}^{-1}$ and $798 \mathrm{~cm}^{-1}$ is assigned to $\mathrm{C}=\mathrm{S}$. In the lower energy region, the intense sharp 
peak observed at $649 \mathrm{~cm}^{-1}$ is due to the N-H out-of plane bending vibrations [12,13]. The band at $999 \mathrm{~cm}^{-1}$ is due to N-N vibration. The band observed at $1621 \mathrm{~cm}^{-1}$ indicating that sulphur is involved in metal coordination.

\subsection{UV-Vis. Studies}

Optical window width is an important characteristic of a nonlinear optical material. The UVVisible spectrum of TSCA was obtained between 200 and 1400nm (Fig. 4). There is no absorption band in between 300 and 1200nm. This shows the absence of any overtones and absorbance due to electronic transitions above $280 \mathrm{~nm}$. This illustrates no absorbance in the visible and near IR region, hence it is a potential candidate for nonlinear optical applications. The characteristics absorbance band only observed at $280 \mathrm{~nm}$.

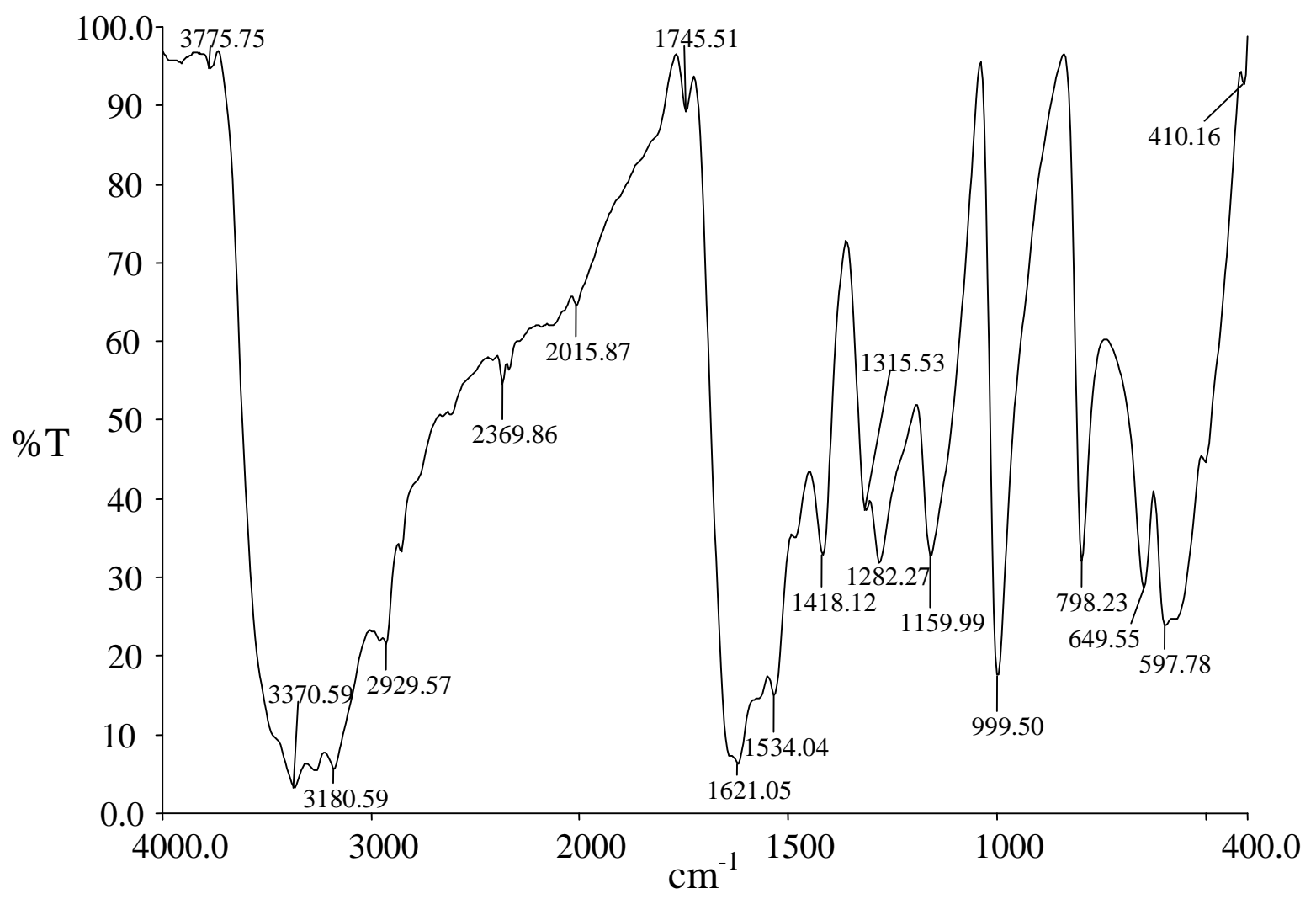

Fig. 3. FTIR spectrum of TSCA single crystal 


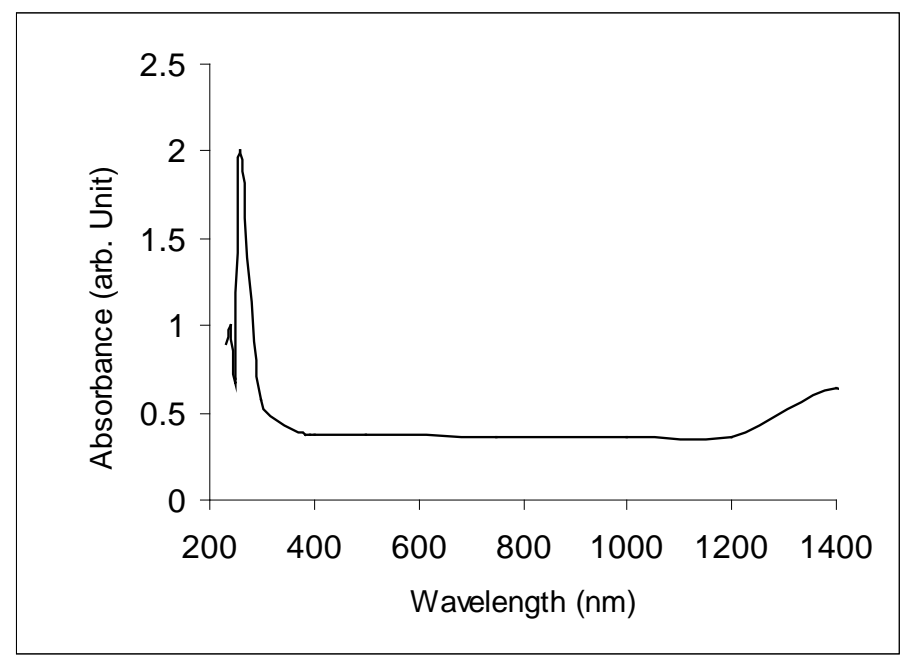

Fig. 4. Optical absorption spectrum of TSCA single crystal

\subsection{Thermal Analyses}

The thermo gravimetric analysis (TGA) and differential thermal analysis (DTA) spectra of the crystal were taken using the instrument STA 1500 thermal analyzer. The TGA and DTA were carried out in nitrogen atmosphere at a heating rate of $20^{\circ} \mathrm{C} / \mathrm{min}$ from 25 to $610^{\circ} \mathrm{C}$. Fig. 5 shows the TGA/DTA traces of TSCA. The first endothermic peak in DTA at $163^{\circ} \mathrm{C}$ corresponds to the phase transformation of TSCA. Hence TSCA is structurally stable upto $163{ }^{\circ} \mathrm{C}$. The major weight loss (27\%) occurring between $182{ }^{\circ} \mathrm{C}$ and $288{ }^{\circ} \mathrm{C}$ suggests that the sample melts and sublimes immediately and then decomposes gradually. This is also indicated by a sharp endothermic peak in the DTA trace of the sample at $225^{\circ} \mathrm{C}$.

\subsection{SHG Test}

The grown TSCA crystals were subjected to Kurtz powder second harmonic generation test to study their NLO efficiencies. The crystalline powder was illuminated using a Spectra Physics Quanta Ray Nd:YAG laser using the first harmonic output of $1064 \mathrm{~nm}$ with a pulse width of 10 ns and a repetition rate of $10 \mathrm{~Hz}$. The second harmonic signal generated in the crystalline sample was confirmed from the emission of green radiation of wavelength $532 \mathrm{~nm}$ collected a monochromator after separating the $1064 \mathrm{~nm}$ pump beam with an IR blocking filter. A photomultiplier tube as used as a detector. It is observed that the measured second harmonic generation efficiency of TSCA crystal was two times ( Table 1) that of potassium dihydrogen phosphate (KDP). 


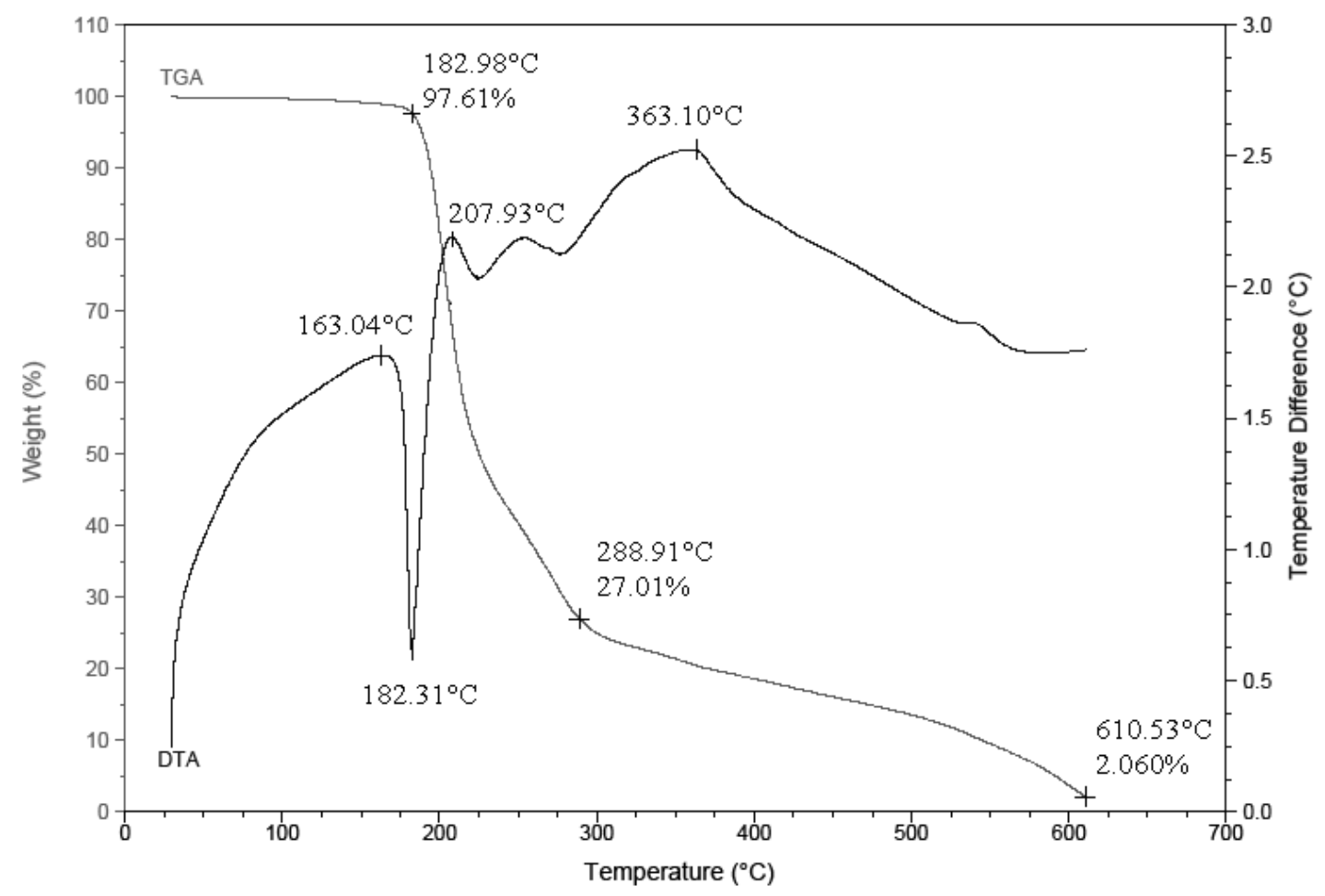

Fig. 5. TG-DTA curves of TSCA single crystal

Table 1 Comparison of SHG signal energy output

\begin{tabular}{lll}
\hline Input power (mJ/pulse) & KDP $(\mathrm{mV})$ & TSCA (mV) \\
\hline 2.8 & 18 & 37 \\
\hline
\end{tabular}

\section{CONCLUSIONS}

We have successfully grown the crystals of thiosemicarbazide cadmium acetate (TSCA) of appreciable size by slow evaporation technique. The crystal system was identified from single crystal X-ray diffraction. The functional groups of the grown compound have been identified by FTIR analysis. TSCA has a wide transparency window from 300 to $1200 \mathrm{~nm}$, which highlights their prospects of applications as NLO materials. Thermal analysis clearly illustrates that the crystal undergoes decomposition above $163^{\circ} \mathrm{C}$. NLO property was confirmed using ND:YAG laser of wavelength $1064 \mathrm{~nm}$ and the efficiency was estimated to be two times higher than KDP. 


\section{REFERENCES}

1 P.N. Prasad, D.J. Williams, Introduction to Nonlinear optical effects in organic molecules and polymers, Wiley, New York, 1991.

2 S.R. Marder, J.E. Sohn, G.D. Stucky, ACS Symp. Proc. 455, Washington, 1991.

3 D.S. Chemla, J. Zyss, Nonlinear optical properties of organic molecules and crystals, Academic Press, New York, 1987.

4 H.S. Nalwa, S. Miyata, Nonlinear optical properties of organic molecules and polymers, CRC Press, Boca Raton, FL, 1996.

5 H.O. Mercy, L.F. Warren, M.S. Webb, C.A. Ebbers, S.P. Velsko, G.C. Kennedy, G.C. Catella, Appl. Opt. 31 (1992) 5051-5060.

6 U. Ramabadran, D.E. Zelmon, G.C. Kennedy, Appl. Phys. Lett. 60 (1992) 2589-2592.

7 P.M. Ushasree, R. Muralidharan, R. Jayavel, P. Ramasamy, J. Crystal Growth 218 (2000) 365-371.

8 V. Kannan, N.P. Rajesh, R. Bairava Ganesh, P. Ramasamy, J. Crystal Growth 269 (2004) 565-569.

9 R. Sankar, C.M. Raghavan, R. Jayavel, Cryst. Growth \& Desi. 7 (2007) 501-505.

10 W.S. Wang, K. Sutter, Ch. Bosshard, Z.Pan, H. Arend, P. Gunter, G. Chapuis, F. Nicolo, Jpn.J. Appl. Phy. 27 (1988) 1138-1141.

11 R. Sankar, C.M. Raghavan, . Mohan Kumar, R. Jayavel, J. Crystal Growth 305 (2007) 156161.

12 M. Mashima, Bull. Chem. Soc. Japan 37 (1964) 974-977.

13 G. Keresztury, M.P. Marzocchi, Chem. Phys. 6 (1974) 117-123.

14 S.K. Kurtz, T.T. Perry, J. Appl. Phys. 39 (1968) 3798-3813. 